\title{
Developing Key Parameters for Green Performance of Partition Wall Blocks
}

\author{
GOH Cheng Siew ${ }^{1}$ and NG Thomas Shiu Tong ${ }^{2}$ \\ ${ }^{1}$ Heriot-Watt University Malaysia, Malaysia \\ ${ }^{2}$ The University of Hong Kong, Hong Kong
}

\begin{abstract}
To promote sustainable construction, it is important to consider green performance of construction materials throughout the life cycle. Selecting inappropriate materials could not only affect the functional performance but also preclude the achievement of green building performance as a whole. Green performance of construction materials has therefore been one of the primary considerations of green building assessment systems. Using partition wall blocks as an example, this paper examines green performance of building materials primarily from the cradle to gate boundaries. Nine key parameters are proposed for the green performance of partition wall blocks. Apart from environmental features, technical performance of partition wall blocks is also taken into consideration since it is the determinant of the lifecycle performance. This paper offers a roadmap to decision makers to make environmentally responsible choices for their materials of internal walls and partitions, and hence provides a potential sustainable solution for green buildings.
\end{abstract}

\section{Introduction}

The construction industry consumes $60 \%$ of raw materials globally [1] and it is the biggest consumers of materials by weight in US compared to other industries [2]. It brings major impacts on the depletion of finite resources, energy consumption, solid waste generation, pollution, and greenhouse gas emission $[1,3,5,6]$. Furthermore, growing public awareness of environmental issues also lead to more attention to sustainable development in construction [4]. A green building paradigm adds significant impetus to the construction industry nowadays in order to reduce environmental impacts as well as improve the sustainability performance of the industry.

To develop green buildings, it is important to incorporate not only appropriate building design and technologies but also suitable building materials in the buildings. Wrong choices in materials specifications, suppliers, constructive technologies and management failure lead to a waste of material and handmade [2]. On the contrary, using appropriate construction materials can improve functional performance, aesthetics, and environmentally friendliness of buildings, in addition to a reduction of cost. As sustainability concept has grown in construction, there is a popularity of using green materials, which establishes the need for more sustainable solutions for construction materials.

A partition wall is an important component of buildings which divides space within a building into rooms or areas in order to enable more effective space utilization [1]. It can either be load-bearing or non-load-bearing, although in most cases it is non-load-bearing. The main functional requirements of partition walls are stability to self-weight, eccentric vertical loads and out of plane horizontal loads, visual, acoustic, and thermal and water resistance [5]. Moreover, contemporary internal partition walls need to take the following requirements into consideration: the speed of organizational and technological change; the increased number and complexity of services to be accommodated; the quality and aesthetic requirements; the need for acoustic separation of compartments; the flexibility for changing the area and organization of the internal spaces; thinner elements (to maximize the net areas); higher environmental life-cycle performance and optimal life cycle costs [6].

Environmental impacts of internal partition walls is attributable to the used material (including embodied energy and thermal properties) and the way the wall is built and maintained [6]. As described by Mateus et al. [6], partition walls have higher contribution to the overall life cycle impacts, as compared to other non-load-bearing elements. To determine key parameters of green performance, it is important to understand the variety of partition wall block, ranging from clay brick to hollow concrete block, autoclaved aerated concrete block, timber stud, lightweight sandwich membrane, fly-ash-lime-phosphogypsum hollow blocks, gypsum plasterboard, gypsum block and etc. $[1,2,6,7]$.

\section{Partition wall blocks and types}

Blocks are one of the important materials of walls and partitions and they have been used extensively as a popular choice in buildings. Hollow blocks or bricks gain the popularity in developing countries due to their low heat dissipation and less raw materials usage for forming cavities [8]. There are a great variety of partition wall blocks which are manufactured using different types of materials. They are also 
made in varying types, thickness, densities and sizes to accommodate for different demands. In general, their sizes are larger than standard bricks. Blocks are chosen because they can provide the better aesthetics and reduced costs by minimising the amount of cut units onsite. Grades of partition blocks are determined by the structural and functional performances of the partition, which are related to the level of activity in adjacent spaces, and the degree of care the partition is likely to receive [9].

\subsection{Concrete blocks}

Concrete blocks can be solid or hollow, with two or three cores or voids. The major materials of concrete blocks are cement, water, sand, gravel (quartz or stone) [10]. The common types of concrete blocks include dense block, lightweight foamed concrete blocks, and autoclaved aerated concrete (AAC) blocks. The shapes and sizes of most common concrete blocks have been standardized to ensure uniform building construction.

\subsection{Gypsum blocks}

Gypsum blocks are commonly made of gypsum plaster, water and additives such as vegetable or wood fiber for better strength. Gypsum blocks do not require sub-structure for erection. Instead of regular mortar, gypsum-based adhesive is used as the bonding agent.

\subsection{Clay blocks}

Clay blocks include honeycomb clay blocks and unfired clay blocks. Honeycomb blocks are formed with a cellular structure of vertical perforations. The perforating structure of honeycomb block reduces material use while giving better thermal performance [10]. For unfired clay blocks, they have excellent environmental credentials because approximate $30 \%$ of materials can be made from alternatives, recycled or secondary resources.

\subsection{Hemp blocks}

Hemp blocks (hempcrete) are blocks produced by blending hemp with a lime and cement binder. Hemp is a fast growing annual plant which is cultivated using different methods in different countries. They are manufactured using a cast or spray-on technology [10]. Hemp blocks are hygroscopic, thus offering a degree of humidity control.

\section{Green performance of blocks}

Selection of appropriate building materials is an important phase in the design process because it impacts not only future functionality of buildings but also their environmental performance [16]. This paper examines green performance of wall blocks principally from the perspective of cradle-to-gate boundaries, even though the impact after the product end-of-life is also taken into account. Cradle-to-gate boundaries evaluate the environmental impacts of materials during the production process, which embeds raw material extraction and processing, processing of secondary material input, transport to the manufacturer, manufacturing, waste processing and disposal of final residues during manufacturing phase [16]. Nine key parameters are identified for assessing green performance of partition wall blocks. They are 1) raw materials, 2) hazardous substances, 3) durability, 4) thermal insulation, 5) sound insulation, 6) fire resistance, 7) energy consumption, 8) waste management, and 9) reusability and recyclability.

\subsection{Raw materials}

There is an increasing trend to use by-products, recycled or waste materials to manufacture partition wall blocks. Vasconcelos et al. [5] proposed to use FGD gypsum (a synthetic industrial by-product), regranulated expanded cork, textile fibers and citric acid (setting time retarder) in manufacturing innovative blocks. Kumar [7] adopted fly ash, lime and gypsum to produce bricks and hollow blocks. Meanwhile, $\mathrm{Wu}$ et al. [8] used shale, fly ash, brick (from building rubbish) and waste paper pulp to produce fired shale hollow blocks. Recycling of those wastes and by-products by incorporating them into building materials is a practical measure to the pollution problem as well as to the conservation of depleting building materials [3].

Apart from waste materials, hemp (a renewable source) is also used as the raw material for partition wall blocks. Hemp is a robust annual crop with remarkable rate of growth, and hemp-lime wall has been demonstrated to be positive to the environment [11].

The use of waste materials and renewable sources (e.g. hemp) should not jeopardise the functional performance of blocks significantly. Several studies have been carried out to demonstrate that the addition of those materials would not affect the strength of blocks significantly [7, 19]. For instance, in the work of Kumar [7], hollow blocks made with high fly ash content can obtain the compressive strength of above $3.5 \mathrm{MPa}$ after 120-day curing, which can replace the burnt clay hollow bricks easily.

\subsection{Hazardous substances}

When more industrial by-products or wastes are used in manufacturing partition wall blocks, it is of concern to take hazardous substances into consideration. Hazardous substances and heavy metals shall be excluded from the use of production of partition wall blocks. If it is impossible to completely eliminate those substances, specific limits of hazardous substances/heavy metal shall apply for their use during manufacture as well as their presence in the final products.

\subsection{Durability}

A partition wall is expected to be serviceable for decades with relatively little maintenance. They need to be strong from frost action, salt crystallisation, biological agencies attack, chemical, aggressive environment and weather $[7,13]$. To be 
durable, blocks shall acquire the minimum compressive strength to withstand the loads.

\subsection{Thermal insulation}

A maximum heat transfer coefficient has to be fulfilled by partition walls such as walls separating heated from non-heated zones, in order to promote more efficient indoor climate control systems [6]. Using high thermal resistance materials reduces the demand of electrical energy for cooling/heating purposes considerably [12]. For instance, introducing holes, cavities or air gaps in concrete blocks can improve the thermal insulation properties of materials since the thermal conductivity of concrete is higher than the thermal conductivity of air [12].

\subsection{Sound insulation}

Sound insulation is a significant attribute in designing internal walls to ensure there is minimum airborne sound transmission resulted from occupancies and traffic noise nuisance [13]. Although airborne sound insulation depends on the superficial mass, light and thin partition technologies, with appropriate design can perform better than conventional heavyweight wall elements [6].

\subsection{Fire resistance}

Partition wall blocks should be incombustible and provide a minimum period of time of fire protection as specified in building regulations [13]. Partition blocks with poor fire safety performance put the users and occupancies in danger. A partition wall block that excels environmentally is definitely not a good alternative if it fails to achieve the required fire properties.

\subsection{Energy consumption}

Lower environmental impacts, light weight and lower energy consumption used in composite wall systems gain growing interest in construction [14]. The embodied energy is the amount of energy consumed due to the raw materials extraction and manufacturing process to produce a finished product [1]. Therefore, the energy consumption (or embodied energy) can be used as an indicator to calculate the emission burden associated with the construction materials or components [1].

As indicated by Broun and Menzies [1], the embodied energy and air emissions associated with construction materials during their extraction, processing and manufacture take the largest percentage of total embodied energy and air emissions in buildings. Therefore, a significant reduction in energy use during the production can considerably improve the environmental performance of buildings. Therefore, blocks shall be designed and manufactured without much use of fossil fuel and electricity. The manufacturing process should be energy conservative, being devoid of sintering or autoclaving [7].

\subsection{Waste management}

The waste generated by each building solution can be managed as construction and demolition (C\&D) waste [2]. C\&D waste is about $13 \%$ to $50 \%$ of solid waste entering landfills in Australia, Finland, Germany, The Netherlands, United Kingdom and The United States [17, 18]. Wastes generate severe impact on the malodours air factor, climate change, land use, marine aquatic eco-toxicity and others [3]. To reduce waste, it is important to decrease the amount of waste generated as well as adopt an effective system for managing unavoidable waste produced [18]. Leiva et al. [20] suggested proper quantification and classification as the important steps of waste management to determine the type and amount of $\mathrm{C} \& \mathrm{D}$ waste available for recycling analysis. To achieve that, a waste management policy covering manufacturing operations shall be implemented.

\subsection{Reusability and recyclability}

The importance of achieving flexibility and increasing adaptability to uses and changeable needs is emphasised [6]. Emmanuel [18] highlights the importance of recyclability and reusability in assessing environmental suitability of wall materials since construction waste has a residual value and can be avoidable. Blocks can be designed to facilitate assembling and disassembling to prevent the production of huge amount of waste. The merits of recycling and reuse is also taken into consideration to reduce the embodied energy and pollution imposed by blocks after their end of life.

\section{Discussion}

Material selection is a key step to attain green performance of buildings. Using building materials with lower embodied energy and carbon emission is one of the approaches to reduce building embodied energy and carbon dioxide emission $[1,15$, 16]. Research $[16,18]$ has been carried out to measure green performance of buildings using embodied energy and carbon dioxide emission.

Although environmental consideration such as carbon footprint or embodied energy is important, green performance should not be evaluated solely on the basis of environmentally friendliness. It should take into account physical-mechanical properties and technological requirements of the evaluated building materials. Emmanuel [18] advocated that the green performance of building materials should be held up against the technical and functional performance as well as economic reality. Environmental performance of building materials should not be developed at the cost of economy and society. If technical requirements are overlooked, the lifetime of materials could be significantly shortened.

By using partition wall blocks as an example, this paper examines green performance by considering their environmental factors as well as technical requirements. Durability, sound insulation, thermal insulation and fire resistance properties are identified as key parameters to ensure "all-round green performance" of blocks. Since wall block is a building material, it is favourable to reflect the environmental impacts incurred within the cradle-to-gate boundaries. 
Cradle-to-gate assessment is a partial product life cycle assessment from the raw materials extraction to the factory gate. It is a useful tool for examining the environmental impacts of raw material production by considering the upstream flow of energy, fuel and raw materials.

With the identified key parameters, suppliers and manufacturers could improve their product development towards greener performance in construction. In the meantime, this paper also assists industry stakeholders and end-users in making greener choices for internal walls and partitions. The demand for and supply of greener building products in built environment can thus be promoted.

\section{Conclusions}

Choosing green materials in buildings can add values to the overall building design and sustainability performance. This paper examines the green performance of blocks principally from the cradle-to-gate boundaries. Nine key parameters are developed to assess green performance of partition wall blocks. In addition to environmental consideration such as energy consumption and waste management, the fulfillment of functional requirements of wall blocks are also essential for green performance. This paper provides a roadmap in guiding decision makers to make environmentally responsible choices for their materials of internal walls and partitions, and hence offers a potential sustainable solution for green buildings. Further research can be carried out to determine innovative design for making the blocks more sustainable, durable, flexible and recyclable.

\section{References}

1. R. Broun, - G. F. Menzies, Life cycle energy and environmental analysis of partition wall systems in the UK, Procedia Engineering, 21 (2011) 864-873

2. A. ández-García, V. Ibáñez-Forés, and M. D. Bovea, Eco-efficiency analysis of the life cycle of interior partition walls: a comparison of alternative solutions, J. Cleaner Production (2015)

3. K. Condeixa, A. Haddad, D. Boer, Life cycle impact assessment of masonry system as inner walls: a case study in Brazil, Constr Build Mater 70 (2014) 141-147

4. M. ..., J. Braet, and A. Audenaert, Life cycle assessment in the construction sector: A review, Ren Sust Energ Rev 26, 379-388 (2013)

5. G. -, et al. Innovative masonry blocks for ,.... walls, presented at XXXVII IAHS World Congress on Housing (2010)
6. R. ... et al., Sustainability assessment of an innovative lightweight building technology for partition walls-Comparison with conventional technologies, Build Environ, 67 (2013) 147-159

7. S. -, Fly ash-lime-phosphogypsum hollow blocks for walls and partitions, Build Environ 38, 2 (2003)

8. J. $\mathrm{Wu}$ et al., Mechanical and thermal tests of an innovative environment-friendly hollow block as self-insulation wall materials, Constr Build Mater 93 (2015)

9. and Construction Authority, Performance specifications for buildable internal partition, Information on http://www.bca.gov.sg/publications/BuildabilitySeries/ot hers/bswall.pdf

10. , Blocks: Concrete masonry and its alternatives, Information on http://www.greenspec.co.uk/building-design/blocks/

11. K. , and A. Miller, Life cycle greenhouse gas emissions of hemp-lime wall constructions in the UK, Resour Conserv Recy 69 (2012) 1-9

12. K. S. Al-Jabri et al., Concrete blocks for thermal insulation in hot climate, Cement Concrete Res, 35, 8 (2005) 1472-1479.

13. E. A.W. Hendry, Masonry walls: materials and _,, Constr Build Mater 15, 8 (2001) 323-330.

14. P. Samani et al, A sustainability assessment of advanced materials for novel housing solutions, Build Environ, 92 (2015) 182-191

15. Y. Saadah, and B. AbuHijleh, Decreasing CO2 … and Embodied Energy during the Construction Phase Using Sustainable Building Materials," Int J Sust Build Technol Urban Dev, 1,2 (2010) 115-120.

16. A. Estokova and M. Porhincak, Environmental analysis of two building material alternatives in structures with the aim of sustainable construction, Clean Envi... Environ Policy, 17, 1 (2015) 75-83.

17. B. A. G. Bossink, and H. J. H. Brouwers, Construction Waste: Quantification and Source Evaluation, J Constr Eng M ASCE 122, 1 (1996) 55-60.

18. R. - Estimating the environmental suitability of wall materials: preliminary results from Sri Lanka, Build Environ 39, 10 (2004) 1253-1261.

19. S. C. Kou, B. J. Zhan, and C. S. Poon, Properties of w... wall blocks prepared with fresh concrete wastes, Constr Build Mater 36 (2012) 566-571.

20. C. Leiva, Solís-Guzmán J, Marrero M, García Arenas C. Recycled Blocks with Improved Sound and Fire Containing Construction and Demolition Waste. Waste Manage 33, 3 (2013) 663-671. 